\title{
PENGARUH MOTIVASI KERJA DAN PEMBERIAN KOMPENSASI TERHADAP KINERJA GURU DI SMA MUHAMMADIYAH PARUNG
}

\author{
Widia Astuti1, Lismiatun² \\ Fakultas Ekonomi, Universitas Pamulang \\ Email: dosen01265@unpam.ac.id ${ }^{1}$,dosen01460@unpam.ac.id ${ }^{2}$
}

\begin{abstract}
Purpose. The purpose of this study was to determine how much influence work motivation and compensation on teacher performance at SMA Muhammadiyah Parung.

Methods. The research method used in this research is quantitative analysis, namely, to examine a particular population or sample, the sampling technique is generally carried out randomly. Collecting data using research instruments, statistical quantitative data analysis to test the hypothesis that has been set, as well as descriptions of research variables with a population of 50 people and a sample of 50 people using a saturated sample. The data analysis technique used a validity test, reliability test, normality test, multicollinearity test, heteroscedasticity test, simple linear regression test, multiple linear regression test, correlation coefficient, determination coefficient, $F$ test, and $t$-test.
\end{abstract}

Findings. The results showed that work motivation (X1) has a positive and significant effect on performance (Y) for Muhammadiyah Parung Senior High School teachers with tcount> table, namely 5.743> 2.012 with a probability value (significance) $=0.000$, which is below 0.05. Compensation (X2) has a positive and significant effect on performance (Y) for Muhammadiyah Parung Senior High School teachers with tcount $>$ table, which is 6,238> 2,012 with a probability value (significance) $=0.000$, which is below 0.05. And work motivation (X1) and compensation (X2) together have a positive and significant effect on the performance (Y) of Muhammadiyah Parung Senior High School teachers with Fcount $>$ Ftable value, namely 25,876>3.20 with probability value (significance) $=0.000$, which is at below 0.05 .

Keywords. Work Motivation, Performance, Compensation

\begin{abstract}
ABSTRAK
Tujuan. Penelitian ini bertujuan untuk mengetahui seberapa besar Pengaruh Motivasi Kerja Dan Pemberian Kompensasi Terhadap Kinerja Guru di SMA Muhammadiyah Parun9.

Metode. Metode penelitian yang digunakan dalam penelitian analisa kuantitatif, yaitu untuk meneliti pada populasi atau sampel tertentu, tekhnik pengambilan sampel pada umumnya dilakukan secara random. Mengumpulkan data mengunakan instrumen penelitian, analisa data bersifat kuantitatif statik dengan tujuan untuk menguji hipotesis yang telah di tetapkan, serta deskripsi variabel penelitian dengan populasi sebanyak 50 orang dan sampel sebanyak 50 orang menggunakan sampel jenuh. Teknik analisis data menggunakan uji validitas, uji realibilitas, uji normalitas, uji multikolionearitas, uji heterokedastisitas, uji regresi linier sederhana, uji regresi linierberganda, koefisien korelasi, koefisien determinasi, uji F dan uji t.
\end{abstract}

Hasil. Hasil penelitian diperoleh Motivasi kerja (X1) berpengaruh positif dan signifikan terhadap kinerja $(\mathrm{Y})$ pada guru SMA Muhammadiyah Parung dengan nilai thitung $>$ ttabel yaitu $5.743>2.012$ dengan nilai probabilitas (signifikansi) $=0.000$ yaitu berada di bawah 
0.05. Kompensasi (X2) berpengaruh positif dan signifikan terhadap kinerja (Y) pada guru SMA Muhammadiyah Parung dengan nilai thitung $>$ ttabel yaitu $6.238>2.012$ dengan nilai probabilitas (signifikansi) $=0.000$ yaitu berada di bawah 0.05. Dan motivasi kerja (X1) dan Kompensasi (X2) secara bersama-sama berpengaruh positif dan signifikan terhadap kinerja (Y) pada guru SMA Muhammadiyah Parung dengan nilai Fhitung > nilai Ftabel yaitu $25.876>3.20$ dengan nilai probabilitas (signifikansi) $=0.000$ yaitu berada di bawah 0.05

\section{Kata Kunci. Motivasi Kerja, Kompensasi, Kinerja}

\section{Pendahuluan}

Salah satu tujuan pendidikan adalah untuk menciptakan manusia yang berkualitas. Kualitas manusia yang dibutuhkan oleh bangsa Indonesia pada masa yang akan datang adalah yang mampu menghadapi persaingan yang semakin ketat dengan bangsa lain di dunia. Kualitas manusia Indonesia tersebut dihasilkan melalui penyelenggaraan pendidikan yang bermutu (Pramudyo, 2010:1) Perlu upaya untuk memperbaiki kualitas pendidikan di Indonesia pada umumnya dan guru di SMA MUHAMMADIYAH PARUNG perbaikan yang menyeluruh terhadap unsur-unsur yang saling terkait di dalamnya. Salah satu unsur yang mempunyai peranan sangat penting dalam meningkatkan kualitas pendidikan tersebut adalah tenaga pendidik, dalam hal ini adalah guru (Pramudyo, 2010:1).

Guru merupakan salah satu komponen esensial dalam suatu sistem pendidikan di SMA MUHAMMADIYAH PARUNG. Peran, tugas, dan tanggungjawab guru sangat bermakna dalam mewujudkan tujuan pendidikan nasional, yaitu mencerdaskan kehidupan bangsa, meningkatkan kualitas manusia Indonesia, meliputi kualitas iman dan takwa, akhlak mulia, dan penguasaan ilmu pengetahuan, teknologi, dan seni, serta mewujudkan masyarakat Indonesia yang maju, adil, makmur, dan beradab (Pramudyo, 2010:2).

Kinerja merupakan hasil kerja yang dicapai seseorang dalam melaksanakan tugastugas yang dibebankan kepadanya. Kinerja guru meliputi kualitas dan kuantitas output serta keandalan dalam bekerja. guru dapat bekerja dengan baik apabila memliki kinerja yang tinggi sehingga dapat menghasilkan kerja yang baik pula(Nasrudin, 2010:237). Melihat posisi guru yang penting dalam pendidikan bangsa tentu saja kinerja guru menjadi salah satu tolak ukur dalam menentukan baik tidaknya guru dalam melaksanakan tugasnya, Apabila guru mempunyai kinerja yang baik maka guru akan melakukan tugas dan perannya dengan baik.

Tujuan yang mulia pada saat ini tampaknya sulit tercapai apabila organisasi yang karyawannya tidak bersemangat dalam menjalankan tugas yang dibebankan kepadanya. Setiap organisasi bukan saja mengharapkan karywan yang mampu, cakap, dan trampil, tetapi tidak kalah penting karyawan mau bekerja giat dan berkeinginan untuk mencapai hasil yang maksimal. Kemampuan dan kecakapan tidak ada artinya bagi organisasi jika mereka tidak mau bekerja giat. Tujuan pegelolaan sistem kompensasi didalam organisasi adalah untuk menarik dan mempertahankan sumber daya manusia karena organisasi memerlukannya untuk mencapai sasaran-sasarannya.

Agar organisasi dapat berkembang luas dengan segala kegiatan kegiatan yang dilakukan untuk mencapai tujuan yang diinginkan dengan menggunakan sumber daya manusia yang telah tersedia, tetapi untuk mencapai tujuan tersebut, tidak cukup hanya dengan jalan memperoleh karyawan yang dianggap paling kompeten, akan tetapi tidak kalah pentingnya dengan secara terus menerus pimpinan memberikan motivasi dan Kompensasi kepada karyawan agar lebih bersemangat dalam menjalankan tugas-tugasnya di organisasi.

Motivasi kerja mempunyai peranan yang penting dalam hal penumbuhan gairah, merasa senang dan semangat untuk bekerja secara optimal. Karyawan yang memiliki motivasi kerja yang kuat akan mempunyai banyak energi untuk melakukan kegiatan. Seorang karyawan yang memiliki intelegensia cukup tinggi bisa gagal karena kekurangan motivasi. Hasil kerja akan optimal kalau ada motivasi yang tepat. Rendahnya motivasi kerja pada karyawan merupakan gejala yang kurang menguntungkan karena rendahnya motivasi kerja pada mereka menunjukkan adanya sikap acuh tak acuh terhadap kehidupan sosial, termasuk terhadap masa 
depan bangsanya. Keberhasilan ekonomi suatu bangsa sangat ditentukan oleh tinggi rendahnya motif berprestasi warganya, dengan kata lain pembangunan suatu bangsa akan sukses bila motif berprestasi warganya tinggi.

Dalam proses pembelajaran tentu ada kegagalan dan keberhasilannya. Kegagalan karyawan dalam melaksanakan tugas tidak sepenuhnya berasal dari diri karyawan tersebut tetapi bisa juga dari organisasi tidak berhasil dalam memberikan motivasi yang mampu membangkitkan semangat karyawan dalam bekerja. Keberhasilan kerja karyawan tidak lepas dari motivasi karyawan yang bersangkutan. Oleh karena itu pada dasarnya motivasi kerja merupakan faktor yang sangat menentukan keberhasilan karyawan dalam melaksanakan tugas yang dibebankan organisasi kepadanya. Karyawan juga akan lebih termotivasi jika dari hasil kerjanya tersebut mendapatkan kompensasi yang memuaskan dari organisasi sebagai tanda penghargaan atas hasil kerjanya tersebut.

Organisasi tentu tidak bisa lepas dari karyawan, dengan perkembagan teknologi yang pesat kadang-kadang mereka lebih cepat tahu tentang bentuk kehidupan yang jauh disana maupun sekitarnya. Adanya ketergantungan satu sama lain membuat kita perlu menghargai karya orang lain. Apresiasi didunia pendidikan penting adanya dan harus dilakukan untuk memberikan nuansa baru yang bersemangat mencari prestasi demi masa depan organisasi di bawah naungan SMA MUHAMMADIYAH PARUNG menyelenggarakan pendidikan sebagai bentuk partisipasi dalam rangka mencerdaskan kehidupan bangsa Indonesia.

Dari hasil wawancara dan pengamatan yang dilakukan peneliti, diperoleh informasi bahwa beberapa guru menunjukkan indikasi kinerja guru belum optimal yaitu ditunjukkan dengan kurangnya perhatian dan pengarahan yang dilakukan oleh kepala sekolah langsung, terhadap para guru dan juga guru terhadap siswa lulusan, kurangnya dorongan motivasi terhadap usaha-usaha keras kerja guru, penyelesaian tugas-tugas masih banyak tidak sesuai waktu yang telah ditetapkan, serta adanya keraguan dan kurannya kepercayaan masayarakat terhadap kinerja guru di SMA Muhammadiyah Parung ini. Sehingga masyarakat sekitar enggan untuk menyekolahkan anak-anaknya di SMA ini. SMA Muhammadiyah Parung, yang lembaga pendidikannya terletak di Jalan Raya Ciseeng Desa Parung Kabupaten Bogor. Jumlah Guru yang ada di SMA Muhammadiyah Parung, sebanyak 50 orang yang terdiri dari, karyawan tetap: 35 orang dan karyawan tidak tetap (honorer) : 15 orang. SMA Muhammadiyah Parung bergerak di bidang pendidikan ini tetap mengemban visi dan misi pendiri yang direalisasikan dalam visi dan misi Yayasan. Dengan berpedoman pada visi Cerdas, Kreatif, dan Religius maka secara umum menggambarkan keinginan yayasan tersebut mampu bersaing dengan lembaga lembaga pendidikan lainnya dengan berlandaskan kereligiusan. Sebagai Lembaga Pendidikan Islam yang bersifat sosial tentu tidak berfokus mencari profit.

Dengan demikian karyawan yang terlibat dalam karya pendidikan SMA Muhammadiyah Parung adalah mereka yang sungguh - sungguh terpanggil untuk terlibat dalam karya pelayanan dengan rela menerima kompensasi yang hanya dapat memenuhi kebutuhan mereka, artinya kompensasi yang belum sesuai dengan ketentuan umum yang berlaku (aturan gaji pegawai negri sipil dan upah minimum regional) tetapi sesuai dengan kemampuan.

\section{Kajian Pustaka dan Hipotesis}

Motivasi menurut Mangkunegara (2015:93) adalah kondisi yang menggerakan pegawai agar mampu mencapai tujuan dari motifnya, motif merupakan suatu dorongan kebutuhan dalam diri pegawai yang perlu dipenuhi agar pegawai tersebut dapat menyesuaikan diri dengan lingkungannya.

H1: Motivasi Kerja berpengaruh terhadap kinerja

Kompensasi menurut Simmaora (2014:446) adalah semua balas jasa yang diterima seorang karyawan dari perusahaannya akibar dari jasa atau tenaga yang telah diberikannya kepada perusahaan tersebut.

H2: Kompensasi berpengaruh terhadap kinerja

Kinerja menurut Moeheriono (2015) adalah hasil kerja yang dapat dicapai oleh seseorang atau kelompok orang dalam suatu organisasi baik secara kuantitatif, sesuai dengan kewenangan dan tugas tanggungjawab masing-masing, dalam upaya mencapai tujuan 
organisasi yang bersangkutan secara legal, tidak melanggar hukum dan sesuai dengan moral atau etika.

H3: Motivasi Kerja dan Kompensasi berpengaruh terhadap kinerja

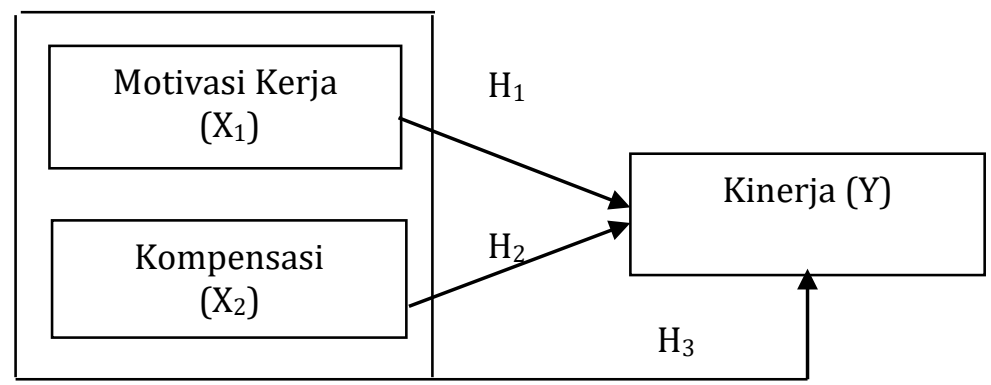

\section{Gambar 1. Model Penelitian}

\section{Metode Penelitian}

Jenis penelitian yang di gunakan penulis adalah dengan analisa kuantatif. Sugiyono (2017:148) mendefinisikan metode penelitian kuantatif dapat diartikan sebagai metode penelitian yang berlandaskan pada filsafat positivme, digunakan untuk meneliti pada populasi atau sampel tertentu, tekhnik pengambilan sampel pada umumnya dilakukan secara random. Mengumpulkan data mengunakan instrumen penelitian, analisa data bersifat kuantitatif statik dengan tujuan untuk menguji hipotesis yang telah di tetapkan.

Dalam penelitian ini bertujuan untuk mengetahui pengaruh motivasi kerja dan pemberian kompensasi terhadap kinerja guru SMA Muhammadiyah Parung.

\section{Analisis Deskriptif}

Menurut Sugiyono (2015:147) "Analisis deskriptif digunakan untuk menganilisis data dengan cara mendeskripsikan atau mengambar data yang terkumpul".

\section{Uji Asumsi Klasik}

Uji asumsi klasik digunakan untuk mengetahui ketepatan sebuah data. Menurut Santoso (2015:342) berpendapat "Sebuah model regresi akan digunakan untuk melakukan peramalan sebuah model yang baik adalah model dengan kesalahan peramalan yang seminimal mungkin. Karena itu, sebuah model sebelum digunakan seharusnya memenuhi beberapa asumsi, yang biasa disebut asumsi klasik". Dalam penelitian ini uji asumsi klasik yang digunakan: Uji Normalitas, Uji Multikolinearitas, Uji Autokorelasi, dan Uji Heterokedastisitas.

\section{Analisis Kuantitatif}

Analisis kuantitatif adalah penelitian untuk menilai kondisi dari nilai pengaruh, dan signifikansi pengaruh tersebut. Dalam penelitian ini analisis kuantitatif yang digunakan: Analisis Regresi Linier Sederhana, Linier Berganda, Uji Parsial (Uji-t), Uji-F, dan Koefisien Determinasi.

\section{Hasil Penelitian dan Pembahasan Analisis Deskriptif}

Analisis desktiptif digunakan untuk menjawab jawaban kuesioner yang disebarkan kepada responden dalam masing-masing variabel lalu diuraikan ke dalam tabel berikut ini: 
Tabel 1. Distribusi Jawaban Kuesioner Variabel Motivasi Kerja $\left(X_{1}\right)$

\begin{tabular}{|c|c|c|c|c|c|c|c|c|c|}
\hline No & PERNYATAAN & SS & $\mathbf{S}$ & $\mathbf{R}$ & TS & STS & $\begin{array}{l}\text { Skor } \\
\text { Total }\end{array}$ & $\begin{array}{l}\text { Rata- } \\
\text { Rata } \\
\text { Skor }\end{array}$ & Ket \\
\hline \multicolumn{10}{|c|}{ Kebutuhan Fisiologis } \\
\hline 1 & $\begin{array}{l}\text { Saya merasa puas dengan } \\
\text { tunjangan kesejahteraan yang } \\
\text { diberikan oleh perusahaan }\end{array}$ & 10 & 30 & 8 & 2 & 0 & 198 & 3.96 & Baik \\
\hline 2 & $\begin{array}{l}\text { Saya mendapatkan dorongan dari } \\
\text { pimpinan dengan diberikannya } \\
\text { bonus tambahan apabila baik } \\
\text { dalam bekerja. }\end{array}$ & 7 & 43 & 0 & 0 & 0 & 207 & 4.14 & Baik \\
\hline \multicolumn{10}{|c|}{ Kebutuhan Keamanan } \\
\hline 3 & $\begin{array}{l}\text { Saya tidak akan pernah takut dari } \\
\text { bahaya yang ada di perusahaan } \\
\text { baik dari internal maupun } \\
\text { eksternal. }\end{array}$ & 8 & 38 & 4 & 0 & 0 & 204 & 4.08 & Baik \\
\hline 4 & $\begin{array}{l}\text { Pimpinan saya memberikan } \\
\text { perlindungan dari ancaman yang } \\
\text { ada diperusahaan. }\end{array}$ & 8 & 25 & 16 & 1 & 0 & 190 & 3.80 & Baik \\
\hline \multicolumn{10}{|c|}{ Kebutuhan Sosial } \\
\hline 5 & $\begin{array}{l}\text { Perusahaan mengadakan acara } \\
\text { yang disponsori oleh perusahaan } \\
\text { seperti ulang tahun perusahaan }\end{array}$ & 7 & 32 & 11 & 0 & 0 & 196 & 3.92 & Baik \\
\hline 6 & $\begin{array}{l}\text { Perusahaan memberikan rekreasi } \\
\text { kepada karyawan pada setiap } \\
\text { episode tertentu agar timbul rasa } \\
\text { kekeluargaan, persahabatan dan } \\
\text { kasih sayang }\end{array}$ & 10 & 38 & 2 & 0 & 0 & 208 & 4.16 & Baik \\
\hline \multicolumn{10}{|c|}{ Kebutuhan Penghargaan } \\
\hline 7 & $\begin{array}{l}\text { Dengan status jabatan yang saya } \\
\text { terima memacu saya untuk } \\
\text { meningkatkan kualitas kerja. }\end{array}$ & 8 & 35 & 7 & 0 & 0 & 201 & 4.02 & Baik \\
\hline 8 & $\begin{array}{l}\text { Saya bekerja untuk mencapai } \\
\text { prestasi kerja yang baik. }\end{array}$ & 11 & 34 & 4 & 1 & 0 & 205 & 4.10 & Baik \\
\hline \multicolumn{10}{|c|}{ Kebutuhan Aktualisasi Diri } \\
\hline 9 & $\begin{array}{l}\text { Dalam bekerja saya selalu } \\
\text { mengemukakan ide-ide terhadap } \\
\text { tugas yang telah diberikan. }\end{array}$ & 10 & 32 & 7 & 1 & 0 & 201 & 4.02 & Baik \\
\hline \multirow[t]{3}{*}{10} & $\begin{array}{l}\text { Saya mempunyai kemampuan } \\
\text { untuk bertindak tegas dalam } \\
\text { menyelesaikan pekerjaan. }\end{array}$ & 8 & 27 & 13 & 2 & 0 & 191 & 3.82 & Baik \\
\hline & $\begin{array}{c}\text { Total Keseluruhan Jawaban } \\
\text { Responden }\end{array}$ & 87 & 334 & 72 & 7 & 0 & 2001 & 40.02 & \\
\hline & Nilai Rata-Rata & \multicolumn{7}{|c|}{4.00} & Baik \\
\hline
\end{tabular}

Tabel 2. Distribusi Jawaban Kuesioner Variabel Disiplin Kerja $\left(\mathrm{X}_{1}\right)$

\begin{tabular}{|c|c|c|c|c|c|c|c|c|c|}
\hline No & PERNYATAAN & SS & $\mathbf{S}$ & $\mathbf{R}$ & TS & STS & $\begin{array}{l}\text { Skor } \\
\text { Total }\end{array}$ & $\begin{array}{l}\text { Rata- } \\
\text { Rata } \\
\text { Skor }\end{array}$ & Ket \\
\hline \multicolumn{10}{|c|}{ Gaji } \\
\hline 1 & $\begin{array}{l}\text { Sekolah sudah memberikan gaji } \\
\text { seesuai dengan standar UMR } \\
\text { yang telah di tentukan }\end{array}$ & 16 & 28 & 4 & 2 & 0 & 208 & 4.16 & Baik \\
\hline 2 & $\begin{array}{l}\text { Gaji yang diterima telah } \\
\text { memenuhi kebutuhan dasar }\end{array}$ & 14 & 36 & 0 & 0 & 0 & 214 & 4.28 & $\begin{array}{l}\text { Sangat } \\
\text { Baik }\end{array}$ \\
\hline \multicolumn{10}{|c|}{ Upah } \\
\hline 3 & $\begin{array}{l}\text { Upah yang diberikan sesuai besar } \\
\text { kecilnya resiko dan tanggung } \\
\text { jawab pekerjaan }\end{array}$ & 14 & 32 & 4 & 0 & 0 & 210 & 4.20 & Baik \\
\hline 4 & $\begin{array}{l}\text { Guru merasa upah yang } \\
\text { diberikan perusahaan mampu }\end{array}$ & 13 & 25 & 12 & 0 & 0 & 201 & 4.02 & Baik \\
\hline
\end{tabular}




\begin{tabular}{|c|c|c|c|c|c|c|c|c|c|}
\hline No & PERNYATAAN & SS & $\mathbf{S}$ & $\mathbf{R}$ & TS & STS & $\begin{array}{l}\text { Skor } \\
\text { Total }\end{array}$ & $\begin{array}{l}\text { Rata- } \\
\text { Rata } \\
\text { Skor }\end{array}$ & Ket \\
\hline & $\begin{array}{l}\text { mencukupi biaya hidup sehari- } \\
\text { hari }\end{array}$ & & & & & & & & \\
\hline \multicolumn{10}{|c|}{ Insentif } \\
\hline 5 & $\begin{array}{l}\text { Insentif yang diberikan sekolah } \\
\text { dapat meningkatkan semangat } \\
\text { kerja }\end{array}$ & 14 & 29 & 7 & 0 & 0 & 207 & 4.14 & Baik \\
\hline 6 & $\begin{array}{l}\text { Insentif diberikan kepada guru } \\
\text { yang berprestasi }\end{array}$ & 13 & 36 & 1 & 0 & 0 & 212 & 4.24 & $\begin{array}{c}\text { Sangat } \\
\text { Baik }\end{array}$ \\
\hline \multicolumn{10}{|c|}{ Tunjangan } \\
\hline 7 & $\begin{array}{l}\text { Tunjangan yang diberikan sesuai } \\
\text { jabatan yang ditempati guru }\end{array}$ & 9 & 36 & 5 & 0 & 0 & 204 & 4.08 & Baik \\
\hline 8 & $\begin{array}{l}\text { Tunjangan kesehatan diberikan } \\
\text { kepada seluruh guru }\end{array}$ & 12 & 32 & 5 & 1 & 0 & 205 & 4.10 & Baik \\
\hline \multicolumn{10}{|c|}{ Bonus } \\
\hline 9 & $\begin{array}{l}\text { Bonus yang diberikan dapat } \\
\text { meningkatkan semangat kerja }\end{array}$ & 14 & 26 & 9 & 1 & 0 & 203 & 4.06 & Baik \\
\hline \multirow[t]{3}{*}{10} & $\begin{array}{l}\text { Bonus yang diberikan sekolah } \\
\text { adil bagi guru }\end{array}$ & 11 & 27 & 11 & 0 & 1 & 197 & 3.94 & Baik \\
\hline & $\begin{array}{c}\text { Total Keseluruhan Jawaban } \\
\text { Responden }\end{array}$ & 206 & 477 & 91 & 25 & 1 & 3262 & 65.24 & \\
\hline & Nilai Rata-Rata & \multicolumn{7}{|c|}{4.08} & Baik \\
\hline
\end{tabular}

Tabel 3. Distribusi Jawaban Kuesioner Variabel Kinerja (Y)

\begin{tabular}{|c|c|c|c|c|c|c|c|c|c|}
\hline NO & PERNYATAAN & SS & $\mathbf{S}$ & $\mathbf{R}$ & TS & STS & $\begin{array}{l}\text { Skor } \\
\text { Total }\end{array}$ & $\begin{array}{l}\text { Rata- } \\
\text { Rata } \\
\text { Skor }\end{array}$ & Ket \\
\hline \multicolumn{10}{|c|}{ Kualitas Kerja } \\
\hline 1 & $\begin{array}{l}\text { Saya mampu melaksanakan } \\
\text { seluruh tugas dengan baik }\end{array}$ & 20 & 24 & 4 & 2 & 0 & 212 & 4.24 & $\begin{array}{c}\text { Sangat } \\
\text { Baik }\end{array}$ \\
\hline 2 & $\begin{array}{l}\text { Saya memiliki keterampilan yang } \\
\text { sesuai dengan bidang kerja }\end{array}$ & 16 & 28 & 4 & 2 & 0 & 208 & 4.16 & Baik \\
\hline \multicolumn{10}{|c|}{ Kuantitas Kerja } \\
\hline 3 & $\begin{array}{l}\text { Saya mampu melaksanakan } \\
\text { seluruh tugas dengan baik }\end{array}$ & 14 & 29 & 6 & 1 & 0 & 206 & 4.12 & Baik \\
\hline 4 & $\begin{array}{l}\text { Saya memiliki keterampilan yang } \\
\text { sesuai dengan bidang kerja }\end{array}$ & 11 & 30 & 7 & 2 & 0 & 200 & 4.00 & Baik \\
\hline \multicolumn{10}{|c|}{ Konsistensi } \\
\hline 5 & $\begin{array}{l}\text { Saya bekerja sesuai dengan job } \\
\text { description yang berlaku di } \\
\text { perusahaan }\end{array}$ & 13 & 25 & 9 & 3 & 0 & 198 & 3.96 & Baik \\
\hline 6 & $\begin{array}{l}\text { Karyawan saat ini memiliki } \\
\text { pengetahuan } \\
\text { pekerjaannya masing-masing }\end{array}$ & 10 & 28 & 10 & 2 & 0 & 196 & 3.92 & Baik \\
\hline \multicolumn{10}{|c|}{ Kerjasama } \\
\hline 7 & $\begin{array}{l}\text { Saya dapat bekerjasama dengan } \\
\text { baik dengan sesama karyawan }\end{array}$ & 4 & 33 & 12 & 1 & 0 & 190 & 3.80 & Baik \\
\hline 8 & $\begin{array}{l}\text { Kerjasama antar karyawan dapat } \\
\text { menghasilkan hasil kerja yang } \\
\text { baik }\end{array}$ & 11 & 36 & 3 & 0 & 0 & 208 & 4.16 & Baik \\
\hline \multicolumn{10}{|c|}{ Sikap } \\
\hline 9 & $\begin{array}{lrr}\text { Karyawan } & \text { yang ada } & \text { saat ini } \\
\text { memiliki } & \text { sikap } & \text { saling } \\
\text { menghargai dan } & \text { saling } \\
\text { menghormati antar karyawan }\end{array}$ & 10 & 37 & 3 & 0 & 0 & 207 & 4.14 & Baik \\
\hline \multirow[t]{3}{*}{10} & $\begin{array}{l}\text { Hubungan antar atasan dan } \\
\text { bawahan saat ini sudah terjalin } \\
\text { dengan baik }\end{array}$ & 15 & 28 & 5 & 2 & 0 & 206 & 4.12 & Baik \\
\hline & $\begin{array}{c}\text { Total Keseluruhan Jawaban } \\
\text { Responden }\end{array}$ & 124 & 298 & 63 & 15 & 0 & 2031 & 40.62 & \\
\hline & Nilai Rata-Rata & & & & 4.06 & & & & Baik \\
\hline
\end{tabular}




\section{Uji Kualitas Data}

Tabel 4. Hasil Uji Validitas

\begin{tabular}{|c|c|c|c|c|}
\hline Variabel & Butir Pernyataan & $\mathbf{r}_{\text {hitung }}$ & $\mathbf{r}_{\text {tabel }}$ & Keterangan \\
\hline \multirow{10}{*}{$\begin{array}{c}\text { Motivasi } \\
\text { Kerja } \\
\left(\mathrm{X}_{1}\right)\end{array}$} & 1 & 0,698 & 0,300 & Valid \\
\hline & 2 & 0,550 & 0,300 & Valid \\
\hline & 3 & 0,642 & 0,300 & Valid \\
\hline & 4 & 0,734 & 0,300 & Valid \\
\hline & 5 & 0,628 & 0,300 & Valid \\
\hline & 6 & 0,703 & 0,300 & Valid \\
\hline & 7 & 0,681 & 0,300 & Valid \\
\hline & 8 & 0,647 & 0,300 & Valid \\
\hline & 9 & 0,672 & 0,300 & Valid \\
\hline & 10 & 0,575 & 0,300 & Valid \\
\hline \multirow{10}{*}{$\begin{array}{c}\text { Kompensasi } \\
\left(\mathrm{X}_{2}\right)\end{array}$} & 1 & 0,541 & 0,300 & Valid \\
\hline & 2 & 0,429 & 0,300 & Valid \\
\hline & 3 & 0,565 & 0,300 & Valid \\
\hline & 4 & 0,600 & 0,300 & Valid \\
\hline & 5 & 0,444 & 0,300 & Valid \\
\hline & 6 & 0,499 & 0,300 & Valid \\
\hline & 7 & 0,435 & 0,300 & Valid \\
\hline & 8 & 0,308 & 0,300 & Valid \\
\hline & 9 & 0,577 & 0,300 & Valid \\
\hline & 10 & 0,493 & 0,300 & Valid \\
\hline \multirow{10}{*}{ Kinerja (Y) } & 1 & 0,736 & 0,300 & Valid \\
\hline & 2 & 0,824 & 0,300 & Valid \\
\hline & 3 & 0,834 & 0,300 & Valid \\
\hline & 4 & 0,806 & 0,300 & Valid \\
\hline & 5 & 0,769 & 0,300 & Valid \\
\hline & 6 & 0,483 & 0,300 & Valid \\
\hline & 7 & 0,331 & 0,300 & Valid \\
\hline & 8 & 0,683 & 0,300 & Valid \\
\hline & 9 & 0,374 & 0,300 & Valid \\
\hline & 10 & 0,829 & 0,300 & Valid \\
\hline
\end{tabular}

Berdasarkan tabel diatas dapat dilihat bahwa untuk masing-masing pernyataan pada variabel seluruh item terbukti valid, karena nilai $r_{\text {hitung }}>r_{\text {tabel. }}$.

Tabel 5. Uji Reliabilitas Variabel Motivasi Kerja $\left(\mathrm{X}_{1}\right)$

Reliability Statistics

\begin{tabular}{|r|r|}
\hline $\begin{array}{c}\text { Cronbach's } \\
\text { Alpha }\end{array}$ & N of Items \\
\hline .843 & 10 \\
\hline
\end{tabular}

Tabel 6. Uji Reliabilitas Variabel Disiplin Kerja $\left(\mathrm{X}_{2}\right)$

Reliability Statistics

\begin{tabular}{|r|r|}
\hline $\begin{array}{c}\text { Cronbach's } \\
\text { Alpha }\end{array}$ & N of Items \\
\hline .776 & 10 \\
\hline
\end{tabular}


Tabel 7. Uji Reliabilitas Variabel Kinerja (Y)

Reliability Statistics

\begin{tabular}{|r|r|}
\hline $\begin{array}{c}\text { Cronbach's } \\
\text { Alpha }\end{array}$ & N of Items \\
\hline .868 & 10 \\
\hline
\end{tabular}

Dengan demikian, berdasarkan hasil perhitungan tabel di atas dapat dilihat bahwa nilai $\mathrm{r}_{\mathrm{ca}}$ lebih besar dari 0,6 sehingga instrumen penelitian dapat dikatakan reliabel.

\section{Uji Asumsi Klasik Uji Normalitas}

Hasil pengujian normalitas data pada variabel kebijakan hutang, keputusan investasi terhadap nilai perusahaan di peroleh hasil :

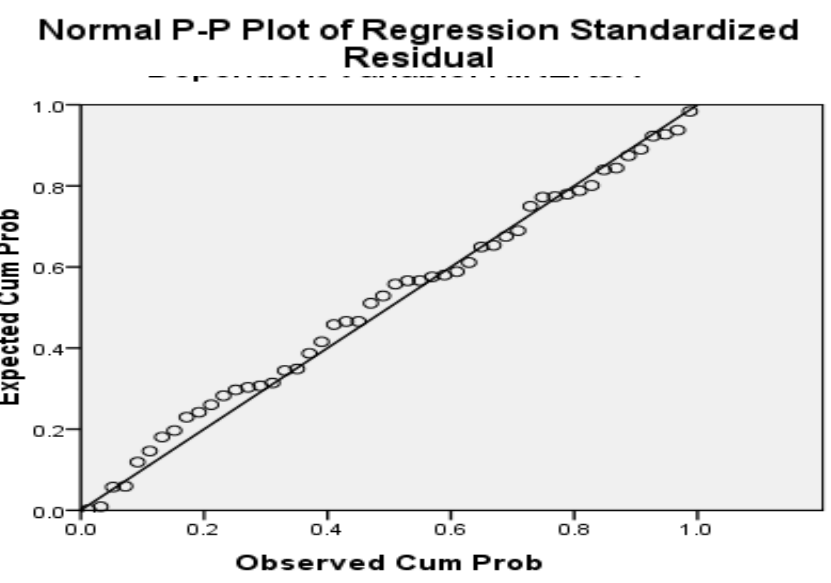

Gambar 2. Hasil Uji Normalitas

Dari hasil uji normalitas yang ada, dengan melihat tampilan grafik normal plot dapat disimpulkan bahwa grafik normal plot terlihat titik - titik menyebar disekitar garis diagonal, serta mengikuti arah garis diagonal. Dapat dikatakan bahwa distribusi data model regresi ini adalah normal.

Adapun untuk menguji kebenaran data apakah normal atau tidak, maka dalam uji normalitas ini dilakukan dengan menggunakan uji Kolmogorov-Simirnov Test. Uji tersebut dapat dilihat pada tabel berikut :

Tabel 8. Hasil Uji Kolmogorov-Simirnov Test

\begin{tabular}{|l|l|r|}
\hline \multicolumn{2}{|l|}{} & $\begin{array}{c}\text { Unstandardize } \\
\text { d Residual }\end{array}$ \\
\hline $\mathrm{N}$ & Mean & 50 \\
\cline { 2 - 3 } Normal Parameters & a,b & .0000000 \\
\hline \multirow{2}{*}{ Most Extreme Differences } & Std. Deviation & 3.52910266 \\
\cline { 2 - 3 } & Absolute & .095 \\
\cline { 2 - 3 } & Positive & .066 \\
\cline { 2 - 3 } & Negative & -.095 \\
\hline \multicolumn{2}{|l|}{ Test Statistic } & .095 \\
\hline Asymp. Sig. (2-tailed) & $.200^{\text {c,d }}$ \\
\hline
\end{tabular}

a. Test distribution is Normal.

b. Calculated from data.

c. Lilliefors Significance Correction.

$\mathrm{d}$. This is a lower bound of the true significance.

Sumber : data diolah (SPSS ver. 21.0) 
Berdasarkan tabel diatas dapat kita lihat bahwa nilai Asymp.Sig.(2-tiled) sebesar 0.200. pada umumnya syarat lolos uji normalitas adalah nilai Asymp.Sig.(2-tiled) lebih besar dari 0.05. berdasarkan hasil perhitungan yang ada, data dalam penelitian ini dikatakan normal karena 0.200 lebih besar dari 0.05 sehingga bisa dikatakan data yang ada lolos dalam uji normalitas tersebut.

\section{Uji Multikolinearitas}

Uji ada tidaknya multikolinieritas dengan melihat Tolerence dan VIF. Semakin kecil nilai tolerance dan semakin besar nilai VIF maka semakin mendekati masalah multikolineritas. Jika tolerance $>0,1$ dan $\mathrm{VIF}<10$. Berikut dapat dilihat dari tabel di bawah ini :

Tabel 9. Hasil Uji Multikolinearitas

Coefficients $^{\mathrm{a}}$

\begin{tabular}{|c|c|c|c|c|c|c|c|c|}
\hline \multirow{2}{*}{\multicolumn{2}{|c|}{ Model }} & \multicolumn{2}{|c|}{$\begin{array}{l}\text { Unstandardized } \\
\text { Coefficients }\end{array}$} & \multirow{2}{*}{$\begin{array}{c}\begin{array}{c}\text { Standardized } \\
\text { Coefficients }\end{array} \\
\text { Beta }\end{array}$} & \multirow[b]{2}{*}{$\mathrm{t}$} & \multirow[b]{2}{*}{ Sig. } & \multicolumn{2}{|c|}{ Collinearity Statistics } \\
\hline & & B & Std. Error & & & & Tolerance & VIF \\
\hline \multirow[t]{3}{*}{1} & (Constant) & -1.613 & 5.930 & & -.272 & .787 & & \\
\hline & MOTIVASI & .430 & .157 & .357 & 2.745 & .009 & .597 & 1.675 \\
\hline & KOMPENSASI & .383 & .113 & .442 & 3.396 & .001 & .597 & 1.675 \\
\hline
\end{tabular}

a. Dependent Variable: KINERJA

Sumber : Pengolahan Data SPSS, 2021.

Dari hasil uji multikolinieritas menunjukkan bahwa nilai tolerance dan VIF pada variabel independen tersebut menunjukkan bahwa tidak terjadi multikolinearitas karena nilai tolerance pada variabel independen $0.597>0.10$ dan nilai VIF $1.675<10$. Sehingga dapat disimpulkan bahwa model regresi pada penelitian ini tidak terjadi gangguan multikolinieritas.

\section{Uji Heterokedastisitas}

Model regresi yang baik adalah tidak adanya masalah heteroskedastisitas. Hasil Uji Heteroskedastisitas dapat di lihat pada gambar berikut ini :

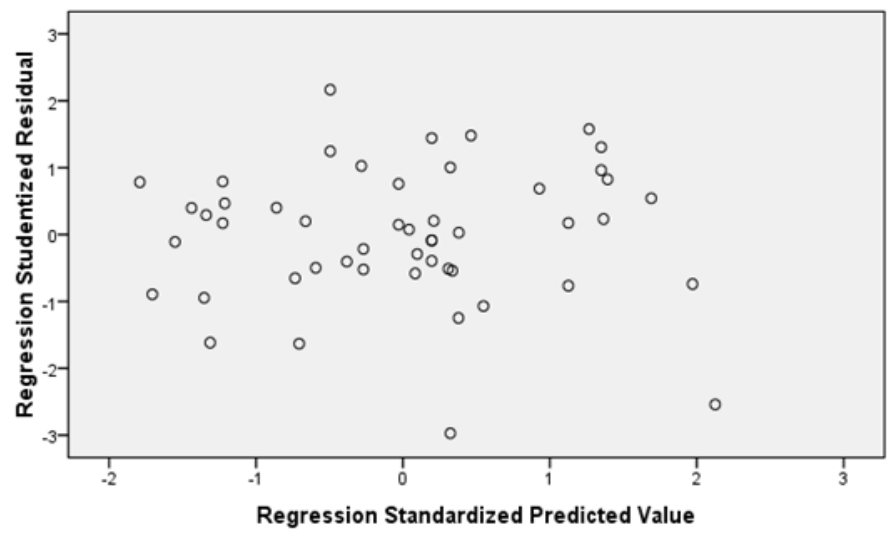

Gambar 3. Hasil Heteroskedastisitas

Deteksi ada atau tidaknya heteroskedastisitas dapat dilakukan dengan melihat ada tidaknya pola tertentu pada grafik scatteplot antara SRESID dan ZPRED. Pada gambar diatas, terlihat bahwa titik - titik yang ada telah menyebar di atas dan dibawah angka nol pada sumbu Y dan tidak terlihat pola tertentu. Dengan demikian dalam model ini tidak terjadi gejala heteroskedastisitas. Sehingga model regresi layak dipakai dalam penelitian karena telah memenuhi asumsi-asumsi dalam Uji Heterokedastisitas. 
Model regresi yang baik mensyaratkan tidak adanya masalah autokorelasi, untuk mendeteksi ada tidaknya autokorelasi dengan melakukan uji Durbin-Watson.

Tabel 10. Hasil Uji Autokorelasi Metode Uji Durbin - Watson Model Summaryb

\begin{tabular}{|c|c|c|c|c|c|}
\hline Model & $\mathrm{R}$ & R Square & $\begin{array}{l}\text { Adjusted R } \\
\text { Square }\end{array}$ & $\begin{array}{l}\text { Std. Error of the } \\
\text { Estimate }\end{array}$ & Durbin-Watson \\
\hline 1 & $659^{a}$ & .435 & .411 & 3.603 & 2.305 \\
\hline
\end{tabular}

a. Predictors: (Constant), Kompensasi, Motivasi Kerja

b. Dependent Variable: Kinerja

Sumber : data diolah (SPSS ver. 21.0)

Nilai Durbin - Watson sebesar 2.305 lebih besar dari batas atas (du) yakni 1.6413 dan kurang dari (4-du) 4-1.6413 atau DW = $2.305>1.6413$, DW = 2.305 < (4-1.6413), maka sebagaimana dasar pengambilan keputusan dalam uji durbin watson diatas, dapat disimpulkan bahwa tidak terdapat masalah atau gejala autokorelasi. Dengan demikian maka analisis regresi linear berganda untuk uji hipotesis penelitian dapat dilanjutkan.

\section{Analisis Kuantitatif Regresi Linier Sederhana}

Tabel 11. Hasil Uji Regresi Linier Sederhana Variabel Motivasi Kerja $\left(X_{1}\right)$ Terhadap Kinerja (Y) Coefficients $^{\mathbf{a}}$

\begin{tabular}{|l|l|r|r|r|}
\hline \multirow{2}{*}{ Model } & \multicolumn{2}{c|}{ Unstandardized Coefficients } & \multicolumn{2}{c|}{ Standardized Coefficients } \\
\cline { 3 - 6 } \multicolumn{2}{|l|}{1} & B & Std. Error & Beta \\
\hline \multirow{2}{*}{1} & (Constant) & 9.872 & 5.379 & \\
\cline { 2 - 5 } & MOTIVASI & .768 & .134 & .638 \\
\hline
\end{tabular}

a. Dependent Variable: KINERJA

Sumber : Pengolahan Data SPSS 2021

Dari hasil diatas menjelaskan bahwa :

a. Nilai konstanta intersep sebesar 9.872 merupakan konstanta (a). Menyatakan bahwa kalau $\mathrm{X}=0$, maka nilai $\mathrm{Y}=9.872$.

b. Nilai koefisien regresi variabel motivasi kerja terhadap kinerja adalah sebesar 0.768 . Hal ini berarti jika motivasi kerja naik 1 satuan maka akan meningkatkan kinerja sebesar 0.768 .

Tabel 12. Hasil Uji Regresi Linier Sederhana Variabel Kompensasi $\left(X_{2}\right)$ Terhadap Kinerja (Y)

Coefficients $^{\mathbf{a}}$

\begin{tabular}{|l|l|r|r|r|}
\hline \multirow{2}{*}{ Model } & \multicolumn{2}{|c|}{ Unstandardized Coefficients } & \multicolumn{2}{|c|}{ Standardized Coefficients } \\
\cline { 3 - 6 } & B & Std. Error & Beta \\
\hline \multirow{2}{*}{1} & (Constant) & 2.779 & 6.086 & .669 \\
\cline { 2 - 6 } & KOMPENSASI & .580 & .093 & \\
\hline
\end{tabular}

a. Dependent Variable: KINERJA

Sumber : Pengolahan Data SPSS 2021

Dari hasil diatas menjelaskan bahwa :

a. Nilai konstanta intersep sebesar 2.779 merupakan konstanta (a). Menyatakan bahwa kalau $\mathrm{X}=0$, maka nilai $\mathrm{Y}=2.779$.

b. Nilai koefisien regresi variabel kompensasi terhadap kinerja adalah sebesar 0.580 . Hal ini berarti jika kompensasi naik 1 satuan maka akan meningkatkan kinerja sebesar 0.580. 


\section{Regresi Linier Berganda}

Tabel 13. Hasil Uji Regresi Linier Berganda Coefficients $^{\mathbf{a}}$

\begin{tabular}{|c|l|r|r|r|}
\hline \multirow{2}{*}{ Model } & \multicolumn{2}{c|}{ Unstandardized Coefficients } & \multicolumn{2}{c|}{$\begin{array}{c}\text { Standardized } \\
\text { Coefficients }\end{array}$} \\
\cline { 3 - 5 } \multicolumn{2}{|c|}{} & B & \multicolumn{1}{c|}{ Std. Error } & Beta \\
\hline \multirow{3}{*}{1} & (Constant) & -1.613 & 5.930 & .357 \\
\cline { 2 - 5 } & MOTIVASI & .430 & .157 & .442 \\
\cline { 2 - 5 } & KOMPENSASI & .383 & .113 & \\
\hline
\end{tabular}

a. Dependent Variable: KINERJA

Sumber : Pengolahan Data SPSS 2021

Dari tabel uji regresi linier berganda diatas maka diperoleh persamaan sebagai berikut: $\mathrm{Y}=-1.613+0.430 \mathrm{X}_{1}+0.383 \mathrm{X}_{2}$

Dari persamaan di atas maka dapat diinterprestasikan beberapa hal, antara lain :

a. Nilai konstanta intersep sebesar -1.613 merupakan nilai konstanta (a)

b. Nilai koefisien regresi variabel motivasi kerja terhadap kinerja adalah sebesar 0.430 . Hal ini berarti jika variabel motivasi kerja naik 1 satuan maka akan meningkatkan variabel kinerja sebesar 0.430 , dengan asumsi variabel disiplin kerja dianggap konstan.

c. Nilai koefisien regresi variabel kompensasi terhadap kinerja adalah sebesar 0.383 . Hal ini berarti jika variabel kompensasi naik 1 satuan maka akan meningkatkan variabel kinerja sebesar 0.383 , dengan asumsi variabel motivasi kerja dianggap konstan.

\section{Uji Statistik}

\section{Uji-t (Uji Parsial)}

Tabel 14. Hasil Uji Stastistik Uji-t Variabel Motivasi Kerja $\left(\mathrm{X}_{1}\right)$

Terhadap Kinerja (Y)

Coefficients $^{\mathrm{a}}$

\begin{tabular}{|c|l|r|r|r|r|r|}
\hline \multirow{2}{*}{\multicolumn{2}{|c|}{ Model }} & \multicolumn{2}{|c|}{ Unstandardized Coefficients } & $\begin{array}{c}\text { Standardized } \\
\text { Coefficients }\end{array}$ & \multirow{2}{*}{ T } & \multirow{2}{*}{ Sig. } \\
\cline { 3 - 5 } \multicolumn{2}{|c|}{} & B & Std. Error & Beta & & \\
\hline \multirow{2}{*}{1} & (Constant) & 9.872 & 5.379 & & 1.835 & .073 \\
\cline { 2 - 7 } & MOTIVASI & .768 & .134 & .638 & 5.743 & .000 \\
\hline
\end{tabular}

a. Dependent Variable: KINERJA

Sumber : Pengolahan Data SPSS 2021

Berdasarkan tabel diatas diperoleh nilai thitung sebesar 5.743, sedangkan nilai ttabel untuk $n=50$ adalah sebesar 2.012. Jadi karena nilai thitung $>$ ttabel, yaitu $5.743>2.012$, nilai probabilitas (signifikansi) $=0.000$ yaitu berada di bawah 0.05 dengan demikian dapat disimpulkan bahwa terdapat pengaruh yang positif dan signifikan variabel motivasi kerja terhadap kinerja karyawan pada guru SMA Muhammadiyah Parung.

Tabel 15. Hasil Uji Stastistik Uji-t Variabel Kompensasi $\left(\mathrm{X}_{2}\right)$

Terhadap Kinerja (Y)

Coefficients $^{\mathrm{a}}$

\begin{tabular}{|c|l|r|r|r|r|r|}
\hline \multirow{2}{*}{ Model } & \multicolumn{2}{|c|}{$\begin{array}{c}\text { Unstandardized } \\
\text { Coefficients }\end{array}$} & $\begin{array}{c}\text { Standardized } \\
\text { Coefficients }\end{array}$ & \multirow{2}{*}{ T } & \multirow{2}{*}{ Sig. } \\
\cline { 3 - 5 } \multicolumn{2}{|c|}{} & B & Std. Error & Beta & & \\
\hline \multirow{2}{*}{1} & (Constant) & 2.779 & 6.086 & & .457 & .650 \\
\cline { 2 - 7 } & KOMPENSASI & .580 & .093 & .669 & 6.238 & .000 \\
\hline
\end{tabular}

a. Dependent Variable: KINERJA

Sumber : Pengolahan Data SPSS 2021

Berdasarkan tabel diatas diperoleh nilai thitung sebesar 6.238, sedangkan nilai ttabel untuk $n=50$ adalah sebesar 2.012. Jadi karena nilai thitung $>$ ttabel, yaitu $6.238>2.012$, nilai 
probabilitas (signifikansi) $=0.000$ yaitu berada di bawah 0.05 dengan demikian dapat disimpulkan bahwa terdapat pengaruh yang positif dan signifikan variabel kompensasi terhadap kinerja pada guru SMA Muhammadiyah Parung.

Uji-F

Tabel 16. Hasil Uji Stastistik Uji-F

ANOVA $^{b}$

\begin{tabular}{|c|l|r|r|r|r|r|}
\hline \multicolumn{2}{|l|}{ Model } & $\begin{array}{c}\text { Sum of } \\
\text { Squares }\end{array}$ & Df & $\begin{array}{c}\text { Mean } \\
\text { Square }\end{array}$ & F & Sig. \\
\hline \multirow{3}{*}{1} & Regression & 565.874 & 2 & 282.937 & 25.876 & $.000^{\mathrm{a}}$ \\
\cline { 2 - 7 } & Residual & 513.906 & 47 & 10.934 & & \\
\cline { 2 - 7 } & Total & 1.079 .780 & 49 & & & \\
\hline
\end{tabular}

a. Predictors: (Constant), MOTIVASI, KOMPENSASI

b. Dependent Variable: KINERJA

Sumber : Pengolahan Data SPSS 2021

Berdasarkan hasil tabel di atas dapat dijelaskan bahwa pengaruh antara motivasi kerja dan kompensasi terhadap kinerja adalah positif dan signifikan karena nilai Fhitung $>$ nilai Ftabel yaitu $25.876>3.20$, nilai probabilitas (signifikansi) $=0.000$ yaitu berada di bawah 0.05 sehingga dapat disimpulkan bahwa terdapat pengaruh yang positif dan signifikan antara motivasi kerja dan kompensasi secara bersama-sama terhadap kinerja pada guru SMA Muhammadiyah Parung.

\section{Koefisien Determinasi $\left(R^{2}\right)$}

Tabel 17. Hasil Uji Koefisien Determinasi $\left(\mathbf{R}^{2}\right)$ Model Summary

\begin{tabular}{|r|l|r|r|r|}
\hline Model & R & \multicolumn{1}{|c|}{ R Square } & Adjusted R Square & Std. Error of the Estimate \\
\hline 1 & $.638^{\mathrm{a}}$ & .407 & .395 & 3.652 \\
\hline
\end{tabular}

a. Predictors: (Constant), MOTIVASI

Sumber : Pengolahan Data SPSS 2021

Hasil dari nilai R2 (R Square) sebesar 0.407. Hal ini menunjukan bahwa sebesar 40,7\% motivasi kerja memiliki kontibusi pengaruh terhadap kinerja, sedangkan sisanya sebesar $59,3 \%$ dipengaruhi oleh variabel lain yang tidak diteliti dalam penelitian ini.

\section{Pembahasan Penelitian}

\section{Motivasi Kerja Berpengaruh Terhadap Kinerja}

Hasil uji R (koefisien korelasi) sebesar 0.638, sedang hasil koefisien determinasi diperoleh nilai $\mathrm{R}^{2}$ ( $\mathrm{R}$ Square) sebesar 0.407 . Hal ini menunjukan bahwa sebesar $40,7 \%$ motivasi kerja memiliki kontibusi pengaruh terhadap kinerja, sedangkan sisanya sebesar $59,3 \%$ dipengaruhi oleh variabel lain yang tidak diteliti dalam penelitian ini. Sedangkan secara regresi linier sederhana diperoleh persamaan $Y=9.872+0.768 \mathrm{X} 1$. dan secara parsial nilai $t_{\text {hitung }}$ sebesar 5.743 , sedangkan nilai $t_{\text {tabel }}$ untuk $n=50$ adalah sebesar 2.012 . Jadi karena nilai $t_{\text {hitung }}>t_{\text {tabel, }}$ yaitu $5.743>2.012$, nilai probabilitas (signifikansi) $=0.000$ yaitu berada di bawah 0.05 dengan demikian dapat disimpulkan bahwa terdapat pengaruh yang positif dan signifikan variabel motivasi kerja terhadap kinerja karyawan pada guru SMA Muhammadiyah Parung.

\section{Kompensasi Berpengaruh Terhadap Kinerja}

Hasil uji R (koefisien korelasi) sebesar 0.669. Hal ini menunjukkan bahwa terjadi hubungan yang kuat antara kompensasi terhadap kinerja, sedang hasil koefisien determinasi diperoleh nilai $\mathrm{R}^{2}$ ( $\mathrm{R}$ Square) sebesar 0.448. Hal ini menunjukan bahwa sebesar $44,8 \%$ kompensasi memiliki kontibusi pengaruh terhadap kinerja, sedangkan sisanya sebesar 55,2\% dipengaruhi oleh variabel lain yang tidak diteliti dalam penelitian ini. Sedangkan secara regresi 
linier sederhana diperoleh persamaan $\mathrm{Y}=2.779+0.580 \mathrm{X}_{2}$ dan secara parsial nilai $t_{\text {hitung }}$ sebesar 6.238, sedangkan nilai $t_{\text {tabel }}$ untuk $n=50$ adalah sebesar 2.012. Jadi karena nilai $t_{\text {hitung }}>$ $\mathrm{t}_{\text {tabel, }}$ yaitu $6.238>2.012$, nilai probabilitas (signifikansi) $=0.000$ yaitu berada di bawah 0.05 dengan demikian dapat disimpulkan bahwa terdapat pengaruh yang positif dan signifikan variabel kompensasi terhadap kinerja pada guru SMA Muhammadiyah Parung.

\section{Motivasi Kerja dan Kompensasi Berpengaruh Terhadap Kinerja}

Dijelaskan bahwa pengaruh antara motivasi kerja dan kompensasi terhadap kinerja adalah positif dan signifikan karena nilai $\mathrm{F}_{\text {hitung }}>$ nilai $\mathrm{F}_{\text {tabel }}$ yaitu $25.876>3.20$, nilai probabilitas (signifikansi) $=0.000$ yaitu berada di bawah 0.05 sehingga dapat disimpulkan bahwa terdapat pengaruh yang positif dan signifikan antara motivasi kerja dan kompensasi secara bersama-sama terhadap kinerja pada guru SMA Muhammadiyah Parung dan secara regresi linier berganda diperoleh persamaan $\mathrm{Y}=-1.613+0.430 \mathrm{X}_{1}+0.383 \mathrm{X}_{2}$

\section{Kesimpulan}

Motivasi kerja $\left(\mathrm{X}_{1}\right)$ berpengaruh positif dan signifikan terhadap kinerja $(\mathrm{Y})$ pada guru SMA Muhammadiyah Parung dengan nilai $t_{\text {hitung }}>t_{\text {tabel }}$ yaitu $5.743>2.012$ dengan nilai probabilitas (signifikansi) $=0.000$ yaitu berada di bawah 0.05. Kompensasi $\left(\mathrm{X}_{2}\right)$ berpengaruh positif dan signifikan terhadap kinerja (Y) pada guru SMA Muhammadiyah Parung dengan nilai $t_{\text {hitung }}>t_{\text {tabel }}$ yaitu $6.238>2.012$ dengan nilai probabilitas (signifikansi) $=0.000$ yaitu berada di bawah 0.05. Motivasi kerja $\left(\mathrm{X}_{1}\right)$ dan Kompensasi $\left(\mathrm{X}_{2}\right)$ secara bersama-sama berpengaruh positif dan signifikan terhadap kinerja $(\mathrm{Y})$ pada guru SMA Muhammadiyah Parung dengan nilai $\mathrm{F}_{\text {hitung }}>$ nilai $\mathrm{F}_{\text {tabel }}$ yaitu $25.876>3.20$ dengan nilai probabilitas (signifikansi) $=0.000$ yaitu berada di bawah 0.05 .

\section{Daftar Pustaka}

Afandi, P. (2018). Manajemen Sumber Daya Manusia (teori, konsep dan indikator). Riau: Zanafap Publishing

Andrew, E. Sikula. (2015). Manajemen Sumber Daya Manusia. Bandung:PT. Erlangga Arikunto, Suharsimi. (2015). Prosedur Penelitian Suatu Pendekatan Praktek.Jakarta: Rineka Cipta

Bangun, Wilson. (2016). Manajemen Sumber Daya Manusia. Bandung:PT. Erlangga. Barry, Chusway. (2016). Human Resource Management. Jakarta: PT.Alex Media.

D. Arika. (2016). Pengaruh Disiplin Kerja Dan Motivasi Kerja erhadap Kinerja . Bandung:Bappeda

Eman Sulaeman . (2018). Pengaruh disiplin kerja, motivasi dan budaya organisasi Terhadap kinerja karyawan. Jurnal Disrupsi Bisnis. Vol. 01, No.2 ISSN:2621797X

Gozali, Imam. (2017). Aplikasi Analisis Multivariate. Semarang:Universitas Diponegoro

Hasibuan, Malayu S.P. (2016). Manajemen Sumber Daya Manusia. Jakarta:Bumi Aksara

Herman, Sofyandi. (2016). Manajemen Sumber Daya Manusia. Yogyakarta:Graha Ilmu

I Nyoman Marayasa, Anggi Faradila. (2019). Pengaruh Motivasi dan Disiplin Kerja Terhadap Kinerja Karyawan. Jurnal Ekonomi Efektif. Vol. 2, No ISSN:26228882

Limbong, Kesita Nola, Syahputra, Mhd. Rozi, dan Sembiring, Mandiri Cukrado. (2019). Pengaruh Motivasi dan Disiplin Kerja Terhadap Kinerja Karyawan. Jurnal Manajemen. EISSN:2301-6256. Vol. 5 No. 2

Mangkunegara, A.A Prabu Anwar. (2015). Manajemen Sumber Daya Manusia. Bandung:PT. Remaja Rosdakarya 